\title{
A review with comments on herpes simplex encephalitis in adults
}

\author{
Xu-Zheng Zuo, Wei-Ju Tang, Xiu-Ying Chen, Wen Huang \\ Department of Neurology, Xinqiao Hospital, Third Military Medical University, Chongqing 400037, China.
}

Correspondence to: Prof. Wen Huang, Department of Neurology, Xinqiao Hospital, Third Military Medical University, Chongqing 400037, China. E-mail: huang_wen2015@sina.com

How to cite this article: Zuo XZ, Tang WJ, Chen XY, Huang W. A review with comments on herpes simplex encephalitis in adults. Neuroimmunol Neuroinflammation 2017;4:24-7.

\section{Article history: \\ Received: 08-07-2016 \\ Accepted: 20-12-2016 \\ Published: 20-02-2017}

\section{Key words:}

Herpes simplex encephalitis,

adults,

diagnosis,

therapies

\section{ABSTRACT}

Herpes simplex encephalitis (HSE) can cause permanent injury to the brain parenchyma. As such, it is usually treated as a medical emergency for which correct immediate diagnosis and introduction of specific therapies are critical for survival and prognosis. Here, the authors review the current status of diagnosis and treatments and discuss unsolved issues surrounding therapeutic interventions. The authors also highlight the current expectations for future management of HSE.

\section{INTRODUCTION}

Herpes simplex encephalitis (HSE) is an acute infectious disease of the central nervous system (CNS) caused by herpes simplex virus (HSV). It typically occurs in the frontal and temporal lobes, causing hemorrhagic necrotic lesions of brain parenchyma. HSE is the most common cause of sporadic fatal viral encephalitis, ${ }^{[1]}$ accounts for almost $20 \%$ of all cases of encephalitis, ${ }^{[2]}$ and has an annual incidence of 1 in 250,000 to $500,000 .{ }^{[3]}$

In immunocompetent adults, more than $90 \%$ of HSE cases are due to HSV-1, ${ }^{[4]}$ whereas HSV-2 is typically responsible forHSE in immunosuppressed individuals. ${ }^{[5]}$
Unfortunately, this CNS disease is life-threatening, as it can also affect the brainstem preferentially or both hemispheres simultaneously ${ }^{[6]}$ in addition to the frontal and temporal lobes, causing a series of clinical features including cognitive impairment, personality changes, seizures, aphasia, and focal weakness. ${ }^{[7,8]}$

HSE is associated with $70 \%$ mortality in untreated patients. In treated cases, there is also about $30 \%$ mortality and a high-incidence of severe and permanent neurological sequelae, such as memory impairment, personality and behavioral abnormalities, or seizures. ${ }^{[9,10]}$ Because of its high morbidity and mortality, it has become a global public health problem with a huge economic impact on the whole society. 
With the development of the diagnosis, and antiviral therapies, the management of patients with HSE has improved rapidly in recent years. However, acyclovir resistance and a better understanding of pathogens and pathogenesis also represent new challenges.

Here, we review the current status of diagnosis and therapies for HSE and discuss current controversies and expectations for the treatment of this disease.

\section{DIAGNOSIS}

\section{Current status of diagnosis}

HSE is a medical emergency and correct and immediate diagnosis is fundamental for the prognosis and therapeutic interventions. At patient's first presentation a meticulous medical history and a careful neurological examination are critical. Peripheral blood count and cellular morphology, such as lymphocytosis, are also helpful in differential diagnosis. Cerebrospinal fluid (CSF) typically shows a lymphocytosis of $10-200 / \mathrm{mm}^{3}$ (or more) and increased protein of 0.5-1.0 g/L or more. ${ }^{[7]}$ During the early stage of the disease, electroencephalography (EEG) with the evidence of spike and slow wave localization to the temporal lobe might suggest HSE, however, EEG has a sensitivity of approximately $60 \%$ and a specificity of $80 \%$. $^{[11]}$

Virus isolation in cell culture, serological tests for specific antigen or antibody production and brain biopsy play a crucial role for the etiology and diagnosis of HSE. However, all have been now replaced by the detection of HSV using polymerase chain reaction (PCR) in the CSF, that shows a sensitivity of approximately $96 \%$, and a specificity of approximately $99 \% \cdot{ }^{[12]}$

Neuroimaging is also importance in suspected HSE cases. Magnetic resonance imaging (MRI) is more specific and sensitive than computed tomography (CT), because of its non-ionizing radiation, multiplanar imaging capability, improved contrast of soft tissue, and high anatomic resolution. ${ }^{[13,14]}$ Usually MRI shows the abnormalities characteristic of edema and/or enhancement in temporal and frontal lobes, the insular cortex, and the angular gyrus. ${ }^{[15-17]}$ Nowadays, the use of DWI and FLAIR imaging is strongly encouraged, ${ }^{[18]}$ as approximately $5 \%$ HSE patients show a normal MRI at presentation. ${ }^{[19]}$ However, it is worth noting that the sensitivity of a new CT post-processing tool based on frequency-selective nonlinear blending (best-contrast $\mathrm{CT}$ ) seems to be equal to that of DWI and FLAIR, as suggested in a recent study. ${ }^{[20]}$

Unresolved issues in diagnosis

PCR-based test in CSF has been established as a gold standard method for the diagnosis of HSE. However, there is evidence of pseudo-negative result influenced by the time of CSF sample collection: the PCR may be negative for HSV-1 during the first 3 days of the illness, ${ }^{[12]}$ however, if the CSF is re-examined after a few days, the PCR may then become positive. The European consensus report ${ }^{[21]}$ recommends repeating the CSF PCR routinely after 14 days of treatment, although this does not guarantee a positive result at 10 14 days after illness. In particular, it has been previously shown that PCR positive result most commonly occurs during the first week of infection, even in the case of concurrent treatment with acyclovir. ${ }^{[22]}$ In light of these data, clinicians should give full consideration to the patient's clinical manifestations and curative effects to determine if the PCR test on CSF should be repeated.

\section{THERAPY}

\section{Current status of therapy}

Correct immediate introduction of specific therapies could reduce the extent of injury and impact on survival.

\section{Antiviral therapy}

Acyclovir (ACV), a guanosine analogue, targets viral DNA replication and is the most efficient drug for the treatment of HSE. The recommended dose is $10 \mathrm{mg} / \mathrm{kg}$ IV every $8 \mathrm{~h}$ for 14 days. In immunocompromised patients or children under 12 years, the treatment usually lasts for at least 21 days. Therapy should begin as soon as HSE is suspected, in fact treatment delays are usually associated with a significantly poorer disease outcome. ${ }^{[3]}$ Renal toxicity, caused by crystallization of $\mathrm{ACV}$ in the kidneys, can be prevented by hydration and slow infusion rates, however kidney function should be monitored and any sign of renal impairment should be considered. ${ }^{[23]}$

Valacyclovir (VCV), an L-valyl ester prodrug of ACV, which is converted to ACV by the hepatic enzyme VCV hydrolase has been shown to have a better oral bioavailability than $A C V$. A recent study indicated that the administration of VCV at 1,000 mg three times daily result in adequate acyclovir concentrations in the CSF and could be considered an acceptable early treatment for suspected HSE in resource-limited settings. ${ }^{[24]}$

\section{Corticosteroids}

Corticosteroids as an adjunct treatment for HSE are still controversial. One study showed that corticosteroids increase patient benefit ${ }^{25]}$ but they are not routinely recommended ${ }^{[3,16,26]}$ as a large prospective randomised trial is still needed. However, steroid administration is recommended in situations where HSE patients show severe cerebral edema that could result in severe brain 
swelling, coning and death and lumbar puncture is to be avoided. ${ }^{[27]}$

\section{Other therapies}

Supporting therapies are also very important for HSE patients to prevent a variety of complications, such as respiration or cardiac failure, fluid balance disorders and deep vein thrombosis. For patients with increased intracranial pressure, neurointensive care unit management is essential. Clinicians in the UK recommended that the management of HSE should be a participatory process, which is co-produced by health professionals, patients, and their families. ${ }^{[28]}$

\section{Unresolved issues in therapy}

One important issue to consider is whether it is safe to stop acyclovir when the CSF PCR result is negative. The 2012 ABN guidelines recommend that aciclovir might be stopped in immunocompetent patients, if: (a) an alternative diagnosis has been made, or (b) HSV PCR in the CSF is negative on two occasions in a 24-48 $\mathrm{h}$ period and MRI is not characteristic for HSV encephalitis, or (c) HSV PCR in the CSF is negative once after $72 \mathrm{~h}$ from neurological symptoms appearance, with unaltered consciousness, normal MRI (performed after $72 \mathrm{~h}$ from symptoms appearance) and with white cell count in the CSF less than $5 \times 10^{6} / \mathrm{L}$ $(\mathrm{B}, \mathrm{III}){ }^{\left[{ }^{[3]}\right.}$

Another issue to take into account is that the combination of acyclovir with other antiherpetic drugs is either synergistic or additive. A randomized controlled study by The National Institute of Allergy and Infectious Diseases Collaborative Antiviral Study Group showed that, following standard treatment with intravenous ACV for PCR-confirmed HSE, an additional 3-month course of oral VCV therapy did not provide additional benefit. ${ }^{[29]}$

Up to date, there is a common belief that no other drugs can replace ACV for the treatment of HSE and drug combinations are not recommended.

\section{PROSPECTS}

Although ACV treatment in HSE is very effective, patient mortality is still approximately $14-19 \%$ and $45-60 \%$ of the survivors suffer from neuropsychological sequelae. ${ }^{[29]}$ On the other hand, viral resistance is also a potential limitation of HSE therapy.

In this context, there is an urgent clinical need for new therapeutic methods which can result in better clinical outcomes for HSE patients and can prevent viral reactivation or infection. New approaches, such as TLR agonists, ${ }^{[30]}$ IL-1 antagonists ${ }^{[31]}$ or vaccines may be helpful in the future.

On the biological front, mechanisms of virus latent infection/recurrence and analysis of viral gene structure and function need to be further explored using advanced technologies. This might be accelerated by the development of molecular genetics approaches that could draw attention to the genetic conditions of susceptible populations.

\section{Financial support and sponsorship None.}

\section{Conflicts of interest}

There are no conflicts of interest.

\section{Patient consent}

There is no patient involved.

\section{Ethics approval}

This article does not contain any studies with human participants or animals.

\section{REFERENCES}

1. Whitley RJ. Herpes simplex virus. In: Scheld WM, Whitley RJ, Durack DT, editors. Infections of the central nervous system. 2nd ed. Philadelphia: Lippincott-Raven; 1997. p. 73-89.

2. Granerod J, Ambrose HE, Davies NW, Clewley JP, Walsh AL, Morgan D, Cunningham R, Zuckerman M, Mutton KJ, Solomon T, Ward KN, Lunn MP, Irani SR, Vincent A, Brown DW, Crowcroft NS; UK Health Protection Agency (HPA) Aetiology of Encephalitis Study Group. Causes of encephalitis and differences in their clinical presentations in England: a multicentre, population-based prospective study. Lancet Infect Dis 2010;10:835-44.

3. Solomon T, Michael BD, Smith PE, Sanderson F, Davies NW, Hart IJ, Holland M, Easton A, Buckley C, Kneen R, Beeching NJ; National Encephalitis Guidelines Development and Stakeholder Groups. Management of suspected viral encephalitis in adults -- Association of British Neurologists and British Infection Association National Guidelines. J Infect 2012;64:347-73.

4. Aurelius E, Johansson B, Sköldenberg B, Forsgren M. Encephalitis in immunocompetent patients due to herpes simplex virus type 1 or 2 as determined by type-specific polymerase chain reaction and antibody assays of cerebrospinal fluid. J Med Virol 1993;39:179-86.

5. Miller S, Mateen FJ, Aksamit AJ Jr. Herpes simplex virus 2 meningitis: a retrospective cohort study. J Neurovirol 2013;19:166-71.

6. Sureka J, Jakkani RK. Clinico-radiological spectrum of bilateral temporal lobe hyperintensity: a retrospective review. $\mathrm{Br} J$ Radiol 2012;85:e782-92.

7. Kennedy PG, Chaudhuri A. Herpes simplex encephalitis. J Neurol Neurosurg Psychiatry 2002;73:237-8.

8. Whitley RJ, Gnann JW. Viral encephalitis: familiar infections and emerging pathogens. Lancet 2002;359:507-13.

9. Kamei S. Cognitive impairment in patients with bacterial meningitis and encephalitides. Brain Nerve 2016;68:317-27. (in Japanese)

10. Whitley RJ. Herpes simplex virus infections of the central nervous system. Encephalitis and neonatal herpes. Drugs 1991;42:406-27.

11. Soong SJ, Watson NE, Caddell GR, Alford CA Jr, Whitley RJ. Use of brain biopsy for diagnostic evaluation of patients with suspected 
herpes simplex encephalitis: a statistical model and its clinical implications. NIAID Collaborative Antiviral Study Group. J Infect Dis 1991;163:17-22

12. Steiner I, Schmutzhard E, Sellner J, Chaudhuri A, Kennedy PG; European Federation of Neurological Sciences; European Neurologic Society. EFNS-ENS guidelines for the use of PCR technology for the diagnosis of infections of the nervous system. Eur $J$ Neurol 2012;19:1278-91.

13. Marchbank ND, Howlett DC, Sallomi DF, Hughes DV. Magnetic resonance imaging is preferred in diagnosing suspected cerebral infections. BMJ 2000;320:187-8.

14. Dale RC, de Sousa C, Chong WK, Cox TC, Harding B, Neville BG. Acute disseminated encephalomyelitis, multiphasic disseminated encephalomyelitis and multiple sclerosis in children. Brain 2000;123 Pt 12:2407-22.

15. Baringer JR. Herpes simplex virus encephalitis. In: Davis LE, Kennedy PGE, editors. Infectious diseases of the nervous system. Butterworth-Heinemann: Oxford; 2000. p. 139-64.

16. Steiner I, Budka H, Chaudhuri A, Koskiniemi M, Sainio K, Salonen O, Kennedy PG. Viral meningoencephalitis: a review of diagnostic methods and guidelines for management. Eur J Neurol 2010;17:999-e57.

17. Magaz Mde L, Wainsztein V, Maritano J, Gutiérrez MN, Binder F, Ferreyro BL, Angriman F, Waisman G. Clinical characteristics of adult patients with herpetic meningoencephalitis: a nested case control study. Rev Chilena Infectol 2015;32:266-71. (in Spanish)

18. Renard D, Nerrant E, Lechiche C. DWI and FLAIR imaging in herpes simplex encephalitis: a comparative and topographical analysis. $J$ Neurol 2015;262:2101-5.

19. Whitley RJ. Herpes simplex virus infections of the central nervous system. Continuum (Minneap Minn) 2015;21:1704-13.

20. Bongers MN, Bier G, Ditt H, Beck R, Ernemann U, Nikolaou K, Horger M. Improved CT detection of acute herpes simplex virus type 1 encephalitis based on a frequency-selective nonlinear blending: comparison with MRI. AJR Am J Roentgenol 2016;207:1082-8.

21. Cinque P, Cleator GM, Weber T, Monteyne P, Sindic CJ, van Loon AM. The role of laboratory investigation in the diagnosis and management of patients with suspected herpes simplex encephalitis: a consensus report. The EU Concerted Action on Virus Meningitis and Encephalitis. J Neurol Neurosurg Psychiatry 1996;61:339-45.

22. Lakeman FD, Whitley RJ. Diagnosis of herpes simplex encephalitis: application of polymerase chain reaction to cerebrospinal fluid from brain-biopsied patients and correlation with disease. National Institute of Allergy and Infectious Diseases Collaborative Antiviral Study Group. J Infect Dis 1995;171:857-63.

23. Wilson SS, Fakioglu E, Herold BC. Novel approaches in fighting herpes simplex virus infections. Expert Rev Anti Infect Ther 2009; 7:559-68.

24. Pouplin T, Pouplin JN, Van Toi P, Lindegardh N, Rogier van Doorn H, Hien TT, Farrar J, Török ME, Chau TT. Valacyclovir for herpes simplex encephalitis. Antimicrob Agents Chemother 2011;55:3624-6.

25. Kamei S, Sekizawa T, Shiota H, Mizutani T, Itoyama Y, Takasu T, Morishima T, Hirayanagi K. Evaluation of combination therapy using aciclovir and corticosteroid in adult patients with herpes simplex virus encephalitis. J Neurol Neurosurg Psychiatry 2005;76:1544-9.

26. Ramos-Estebanez C, Lizarraga KJ, Merenda A. A systematic review on the role of adjunctive corticosteroids in herpes simplex virus encephalitis: is timing critical for safety and efficacy? Antivir Ther 2014;19:133-9.

27. Kennedy PG, Steiner I. Recent issues in herpes simplex encephalitis $J$ Neurovirol 2013;19:346-50.

28. Cooper J, Kierans C, Defres S, Easton A, Kneen R, Solomon T Diagnostic pathways as social and participatory practices: the case of herpes simplex encephalitis. PLoS One 2016;11:e0151145.

29. Gnann JW Jr, Sköldenberg B, Hart J, Aurelius E, Schliamser S Studahl M, Eriksson BM, Hanley D, Aoki F, Jackson AC, Griffiths P, Miedzinski L, Hanfelt-Goade D, Hinthorn D, Ahlm C, Aksamit A, Cruz-Flores S, Dale I, Cloud G, Jester P, Whitley RJ; National Institute of Allergy and Infectious Diseases Collaborative Antiviral Study Group. Herpes simplex encephalitis: lack of clinical benefit of long-term valacyclovir therapy. Clin Infect Dis 2015;61:683-91.

30. Pérez de Diego R, Mulvey C, Crawford M, Trotter MW, Lorenzo L, Sancho-Shimizu V, Abel L, Zhang SY, Casanova JL, GodovacZimmermann J. The proteome of Toll-like receptor 3-stimulated human immortalized fibroblasts: implications for susceptibility to herpes simplex virus encephalitis. $J$ Allergy Clin Immunol 2013;131:1157-66.

31. Michael BD, Griffiths MJ, Granerod J, Brown D, Keir G, Wnęk G, Cox DJ, Vidyasagar R, Borrow R, Parkes LM, Solomon T. The interleukin-1 balance during encephalitis is associated with clinical severity, blood-brain barrier permeability, neuroimaging changes, and disease outcome. J Infect Dis 2016;213:1651-60. 